\title{
Comparisons of Perceived Training Doses in Champion Collegiate-Level Male and Female Cross-country Runners and Coaches over the Course of a Competitive Season
}

Kyle R. Barnes

\begin{abstract}
Background: Session rating of perceived exertion (SRPE) is a practical tool for coaches to assess internal training load of their athletes. In a sport like cross-country running, that is individual in nature, but has a team training and competition component, information about the association between external and internal load is lacking. Furthermore, there is a need for studies that examine perception of training doses across multiple training cycles including the competitive season as well as between male and female athletes.

Methods: Session RPE, duration, and training load ( $T L_{R P E}=s R P E \times$ duration) of 25 highly trained male and female cross-country runners and their coaches were recorded for every training session (110 days) throughout a collegiate cross-country season. Intensity (SRPE), duration, and TLRPE were compared between coaches and runners by gender separately. Training sessions were also analyzed by those intended by the coaches to be easy, moderate, and hard as well as by training period.

Results: Data from 3024 training sessions were collected, 62\% of which were considered "easy," 18\% "moderate," and 20\% "hard." Men and women rated coach-intended easy sessions significantly harder during each month of the season (effect size $(E S)>2.9, p<0.0001$ ). Men rated moderate intensity sessions significantly higher than coaches (ES $\geq 1.0, p \leq 0.002$ ), whereas females rated hard intensity sessions significantly lower than coaches (ES $>0.5, p<0.008$ ). There was no difference between males and coach's hard sessions $(E S<0.07, p>0.05$ ) or females and coach's moderate sessions ( $E S<0.18, p>0.05$ ). Training intensity and $T L_{R P E}$ tended to increase throughout the season $(p>0.05)$, with a significant increase in moderate and hard intensity sessions in the last training period $(p<0.001)$.

Conclusions: The results indicate the male and female cross-country runners tend to regress to moderate intensity training throughout the cross-country season. Given the success of the athletes in this study, these results show how a simple system for monitoring training such as the SRPE method may improve control of training variables and provide a useful tool for coaches to evaluate training load placed on athletes in a simple, responsive way.
\end{abstract}

Keywords: Training load, Intensity, Session RPE, Running, Periodization 


\section{Key Points}

- There is a difference between coaches and male and female cross-country runner's intentions and perceptions of easy, moderate, and hard intensity training sessions throughout a competitive season.

- The rationale for differences in perceptions of training intensities and loads was not fully elucidated but may be related to differences in coaching supervision during easy and hard training sessions, physiological and psychosocial factors before, during, and after training sessions, communication between coaches and athletes, and/or athlete experience.

- The sRPE method for monitoring training is a practical system coaches can implement to evaluate training load placed on athletes on a day-to-day basis, in a simple, responsive way.

\section{Background}

Previous studies have stressed the importance of periodized training load in enhancing athletic performance and the changes in performance attributable to varying periods of hard and easy training [1-4]. These practicalities are reflected in the practice of coaches who design highly detailed periodized training programs $[3,5]$. Unfortunately, although periodized training programs are in their essence quantitative, there has been great difficulty in finding a way to effectively quantitate training using a single term. Distance runners have often used their training volume (total kilometers or miles run per week) and duration as an index of training with reasonable effectiveness $[2,6]$. However, measurement of training programs as training volume ignores the critical importance of intensity [6]. Therefore, athletes training for endurance performance, the use of volume of training is an inadequate tool because of the overriding importance of intensity.

In response, the session rating of perceived exertion (sRPE) method of monitoring exercise intensity was developed as a modification of the category ratio RPE method [3,7]. The modification involved asking the subject to give a global rating of their perceived exertion for the entire exercise session $\sim 30 \mathrm{~min}$ after the conclusion of an exercise bout rather than rating the momentary level of exertion as is the usual practice with RPE [4, 7]. When this intensity rating is multiplied by the duration of the training session, a single number similar to that of a TRIMP (training impulse) score devised by Banister et al. [8] representing the magnitude of that training session or "training load" is derived. Several papers have used the sRPE method in a variety of settings and have demonstrated its value relative to quantifying exercise training intensities $[1,7,9-11]$ and as the intensity component of larger schemes of evaluating training programs [1, 3, 4, 9-11]. While sRPE method may not represent a superior way of monitoring exercise intensity compared to that of heart rate monitors and global position system tracking, many teams and clubs cannot afford the equipment or time to track, monitor, and analyze such data. Therefore, sRPE represents a practical and efficient way of monitoring the internal load of many athletes that have demands beyond that of just training and competing.

Within a training program of collegiate distance runners, balancing the desired external training load by coaches with the perceived internal training load of athletes represents unique challenges in this environment. This includes trying to optimize performance by maximizing intense training sessions with recovery sessions to elicit specific training adaptations all within the confines of class schedules, practice times, and individual characteristics of each runner [12]. In addition, it is assumed that psychosocial factors, such as an exam at school, also affect the internal training load [13, 14]. Ideally, the internal load matches the external training load, assuming that the prescribed training results in optimal performance for the athlete. However, it is impossible for coaches to be fully aware of the internal load of athlete, especially in team environments. Differences between the training programs designed by coaches and executed by individual and team sport athletes are well established [9-11, 15-25]. It is suggested that this difference is even more pronounced in team sports because training load during group exercise is difficult to control [9], thus providing a plausible explanation for a lack of improvements in performance or the incidence of overtraining syndrome, injury, illness, or maladaptation to training in high-level athletes $[9,10,13,23]$.

In sports like cross-country running, that is individual in nature, but have a team training and competition component, information about the association between external and internal load is lacking. In addition, there is a need for studies that examine perception of training doses across longer time periods that include different types of training cycles including the competitive season. Finally, there is a paucity of data comparing the perceptions of female athletes to coaches in any sport or discipline as well as limited data comparing male runners to coaches. Therefore, the purpose of this study was to investigate and compare the perceptions of training doses between coaches and male and female cross-country runners independently over a full competitive crosscountry season.

\section{Methods}

\section{Subjects}

Twenty-five highly trained cross-country runners (13 male and 12 female) were recruited from the Grand Valley State 
University men's and women's National Collegiate Athletic Association (NCAA) Division II Cross-Country teams. The characteristics of the male and female runners were (mean \pm SD) age $20.2 \pm 1.4$ and $19.7 \pm 1.6 \mathrm{y}$., training history $6.2 \pm 1.3$ and $6.5 \pm 1.1 \mathrm{y}$., height $176.6 \pm 7.8$ and $168.4 \pm 6.5 \mathrm{~cm}$, weight $67.9 \pm 7.1$ and $53.9 \pm 6.0 \mathrm{~kg}$, and percentage body fat $6.4 \pm 1.9$ and $12.4 \pm 3.2$, respectively. Five of the men and six of the women were All-Americans (top 40 runners at NCAA Division II Cross-Country National Championship) and as a team, the Women's team won the NCAA Division II Cross-Country National Championship and the Men's team was the National Runner-up.

For both the men and women's teams, two coaches were responsible for the training programs of both teams. Athletes received a training program with a combination of easy, moderate, and hard runs each week. The athletes trained together as a team 5 days each week ( 6 days per week during weeks that also included a competition) under the supervision of the coaches. The days in which athletes did not train together or under the supervision of the coaches were days in which easy runs were prescribed. The study was approved by Grand Valley State University's Human Research Review Committee (Reference \#: 14-206-H) and performed in accordance with the standards of ethics outlined in the Declaration of Helsinki. All participants provided informed written consent to participate.

\section{Experimental Testing}

Before each training session throughout the entire crosscountry season (110 training days), coaches rated the intended intensity of each training session (session rating of intended exertion, sRIE) on a scale from 0 (rest) to 10 (maximal exertion) (Table 1), for both teams. Because each athlete was expected to run a different total volume of training each week, coaches gave athletes a range of duration (minutes) of training each day depending on the athlete. The duration of the training session including all running activities from the beginning of the warm-up period to the end of the cooldown, but excluded ancillary aspects of training such as drills, resistance training, and stretching. The sRIE was blinded to athletes, but the training prescription was presented to the athlete's in conventional terms (e.g., distance to be run and/or number and distance of intervals to be completed). Descriptive modifiers, usually presented as a particular pace, or percentage of racing pace, were often added, particularly during "hard" high-intensity training sessions. Thirty minutes after each training session, athletes evaluated their own training session by reporting their session rating of perceived exertion (sRPE) in accord with the verbal prompt, "if a friend who did not understand the specific training expressions of athletics
Table 1 Session Rating of Perceived Exertion (SRPE) Scale

\begin{tabular}{ll}
\hline Rating & Verbal anchor $^{\text {a }}$ \\
\hline 0 & Rest \\
1 & Very easy \\
2 & Easy \\
3 & Moderate \\
4 & Sort of hard \\
5 & Hard \\
6 & \\
7 & Very hard \\
8 & Very, very hard \\
9 & Near maximal \\
10 & Maximal \\
\hline
\end{tabular}

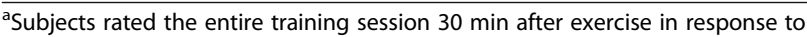
the verbal prompt "if a friend who did not understand the specific training expressions of athletics were to ask you how hard your training session was, how would you reply?"

were to ask you how hard your training session was, how would you reply" [10] (Table 1) along with the training duration of the session using an online training $\log$. Coaches were blinded to the athlete sRPE until after the season was over as to not interfere with the athlete's perception of training intensities. The rationale for rating the intensity (sRPE) of the training session at least $30 \mathrm{~min}$ after the conclusion of training is to prevent particularly hard or easy elements late in the training session from dominating the athletes' perception of the training session $[7,11,26]$. Ratings not reported the same day were not included in the analysis. Both coaches and athletes were given verbal and written description of procedures and were supervised on a daily basis across the cross-country season.

\section{Analysis}

Following all training sessions, multiplication of the sRPE (or sRIE from coaches) by the duration yielded a dimensionless term which we will refer to as training load ( $\left(\mathrm{L}_{\mathrm{RPE}}\right.$ ), and which is conceptually (although not numerically) equivalent to the training impulse (TRIMP) score derived from heart rate monitor training [7]. Means and standard deviations were calculated for intensity (sRPE or sRIE), duration, and $\mathrm{TL}_{\mathrm{RPE}}$ (intensity $\times$ duration) for both coaches and athletes by gender. Training sessions were also divided into those intended by the coaches to be "easy" (RPE <3), "moderate" (RPE $=3-5)$, and "hard" $(\mathrm{RPE}>5)[9,10]$. They were then compared between the coaches' and athletes' perceptions of intensity, duration, and $\mathrm{TL}_{\mathrm{RPE}}$ by using a two-way ANOVA. Furthermore, data for men and women divided up by month were analyzed. Bonferroni-corrected pairwise comparisons used for post hoc analysis was included on the subjects' ratings to determine if a significant difference exists 
between athletes and coaches. Statistical analyses were performed using Statistical Analysis System (SAS) version 9.4 (Cary, NC). $p$ values lower than 0.05 were considered statistically significant.

To determine the magnitude of effects between athletes and coaches, a spreadsheet for post-only crossovers was used [27]. The pre-test value of the dependent variable was included as a covariate to improve precision of the estimate of the effects. Effects were estimated in percent units via log transformation, and uncertainty in the estimate was expressed as $90 \%$ confidence limits. The effect size (ES), which represents the magnitude of the difference between the two conditions in terms of SD, was calculated from the log-transformed data by dividing the change in the mean by the average SD of the two conditions. Magnitudes of effects on outcomes between coaches and athletes were evaluated non-clinically: if the confidence interval overlapped thresholds for small positive and negative values, the effect was deemed unclear; all other effects were reported as the magnitude of the observed value and were evaluated probabilistically as described previously [28]. The threshold values for assessing the magnitude of small, moderate, large, very large, and extremely large effects were $0.2,0.6,1.2,2.0$, and 4.0 of the between-subject standard deviation [29].

\section{Results}

Data from 3024 training sessions were collected from 25 runners (13 male and 12 female) and two coaches, of which $62 \%$ were considered "easy", $18 \%$ "moderate", and $20 \%$ "hard". There was $>99 \%$ reporting compliance from all athletes. Average intensity, duration, and $\mathrm{TL}_{\mathrm{RPE}}$ over the entire cross-country season by the male athletes were $3.92 \pm 1.19$ arbitrary units (AU), $65.7 \pm 13.5 \mathrm{~min}$, and $307.7 \pm 113.5 \mathrm{AU}$; and female athletes were $3.67 \pm 1.02$ AU, 48.4 $\pm 9.3 \mathrm{~min}$, and $210.6 \pm 74.2 \mathrm{AU}$, respectively. Average intensity and $T L_{R P E}$ as prescribed by coaches across the cross-country season was $3.09 \pm 2.43$ and
$238.9 \pm 40.5 \mathrm{AU}$ for men and $3.09 \pm 2.43$ and $189.4 \pm$ 29.9 AU for women, respectively.

Men and women rated sessions intended to be easy by the coach as very large-extremely largely higher (harder) throughout the season (men: Table 2, ES $=2.96 \pm 0.46, p$ $<0.0001$; women: Table 3, ES $=4.39 \pm 0.48, p<0.001$ ). Males and females $\mathrm{TL}_{\mathrm{RPE}}$ was also large-extremely higher (men: Fig. 1a, Table 2, ES $=1.98 \pm 0.37, p<0.0001$; women: Fig. $1 \mathrm{~b}$, Table $3, \mathrm{ES}=3.76 \pm 0.55, p<0.001$ ). Men's intensity during moderate training sessions was largely higher $(\mathrm{ES}=1.21 \pm 0.46, p=0.001)$ than coaches (Table 2), and $\mathrm{TL}_{\mathrm{RPE}}$ was also moderately higher than coaches (Fig. 1a, Table 2, ES $=1.00 \pm 0.36, p=0.002$ ) throughout the season. There was no difference between females and coach's intensity (Table $3, \mathrm{ES}=0.18 \pm 0.48$, $p=0.38$ ) or $\mathrm{TL}_{\mathrm{RPE}}$ (Fig. 1b, Table 3 , $\mathrm{ES}=0.10 \pm 0.46, p=$ 0.61 ) for moderate sessions throughout the season. There was no difference between male runners and coach's perception of hard sessions (Table 2, ES $=0.07 \pm$ $0.46, p=0.91$ ) whereas there was a moderate lower difference in women's rating of hard sessions compared to coaches $(E S=0.91 \pm 0.48, p=0.006)$. There was also no difference in hard sessions $\mathrm{TL}_{\mathrm{RPE}}$ for men (Fig. 1a, Table 2, $\mathrm{ES}=0.03 \pm 0.24, p=0.68$; however, there was a small lower difference in female's hard session $\mathrm{TL}_{\mathrm{RPE}}$ compared to coaches (Fig. 1b, Table 3, ES $=0.53 \pm 0.30, p=0.008$ ).

When examining the breakdown of males and female's intensity (Tables 2 and 3) compared to the coaches by month over the duration of cross-country season, results revealed significant differences between both males and female sRPE and coach sRIE during each month of the season for easy sessions $(p<0.0001)$. There were also significant differences in easy training session $\mathrm{TL}_{\mathrm{RPE}}$ between gender and coach during each month of the season (Fig. 2, Tables 2 and 3, $p<0.001$ ). The $\mathrm{TL}_{\mathrm{RPE}}$ for easy sessions tended to increase from month 1 to month 4 throughout the season $(p>0.12)$ but significantly reduced from month 4 to $5(p=0.005)$ for both males and

Table 2 Male Runners and Coach's Intensity (sRPE and sRIE) and Training Load ( $\left.T L_{R P E}\right)$ According to the Season Period and Intended Session Intensity (mean \pm SD)

\begin{tabular}{|c|c|c|c|c|c|c|c|c|c|c|c|c|}
\hline \multirow{3}{*}{ Season period } & \multicolumn{4}{|l|}{ Easy } & \multicolumn{4}{|l|}{ Moderate } & \multicolumn{4}{|l|}{ Hard } \\
\hline & \multicolumn{2}{|c|}{ Intensity $(\mathrm{AU})^{\mathrm{a}}$} & \multicolumn{2}{|c|}{ Training load $(\mathrm{AU})^{\mathrm{b}}$} & \multicolumn{2}{|c|}{ Intensity (AU) } & \multicolumn{2}{|c|}{ Training load (AU) } & \multicolumn{2}{|c|}{ Intensity (AU) } & \multicolumn{2}{|c|}{ Training load (AU) } \\
\hline & Athlete & Coach & Athlete & Coach & Athlete & Coach & Athlete & Coach & Athlete & Coach & Athlete & Coach \\
\hline 1 & $2.4 \pm 0.5$ & $1.3 \pm 0.5$ & $107 \pm 74$ & $55 \pm 15$ & $4.4 \pm 0.8$ & $3.4 \pm 0.6$ & $435 \pm 141$ & $331 \pm 43$ & $6.9 \pm 0.6$ & $6.8 \pm 1.0$ & $620 \pm 167$ & $593 \pm 120$ \\
\hline 2 & $2.5 \pm 0.5$ & $1.1 \pm 0.3$ & $126 \pm 94$ & $48 \pm 17$ & $4.3 \pm 1.2$ & $3.4 \pm 0.7$ & $412 \pm 139$ & $321 \pm 44$ & $7.1 \pm 1.0$ & $7.1 \pm 1.0$ & $640 \pm 162$ & $630 \pm 107$ \\
\hline 3 & $2.8 \pm 0.9$ & $1.2 \pm 0.5$ & $166 \pm 86$ & $102 \pm 18$ & $4.7 \pm 0.4$ & $3.6 \pm 0.6$ & $522 \pm 170$ & $392 \pm 49$ & $7.4 \pm 0.6$ & $7.3 \pm 0.9$ & $661 \pm 149$ & $650 \pm 99$ \\
\hline 4 & $2.8 \pm 0.9$ & $1.3 \pm 0.5$ & $186 \pm 96$ & $98 \pm 17$ & $4.2 \pm 0.2$ & $3.8 \pm 0.5$ & $446 \pm 170$ & $386 \pm 53$ & $6.9 \pm 0.6$ & $7.7 \pm 0.6$ & $681 \pm 166$ & $705 \pm 111$ \\
\hline $5^{c}$ & $2.1 \pm 0.8$ & $1.5 \pm 0.6$ & $123 \pm 70$ & $82 \pm 69$ & 5.2 & 5.0 & 572 & 499 & 10.0 & 10.0 & 768 & 768 \\
\hline Season average & $2.7 \pm 0.6$ & $1.4 \pm 0.5$ & $157 \pm 88$ & $82 \pm 21$ & $4.4 \pm 0.7$ & $3.6 \pm 0.6$ & $448 \pm 149$ & $351 \pm 46$ & $7.3 \pm 0.7$ & $7.3 \pm 1.0$ & $658 \pm 157$ & $646 \pm 105$ \\
\hline
\end{tabular}

$A U$ arbitrary units, $s R P E$ session rating of perceived exertion, sRIE session rating of intended exertion, $T L_{R P E}$ training load

${ }^{a}$ Intensity assessed as SRPE by athletes or SRIE by coaches on 1-10 scale [10]

${ }^{\mathrm{b}}$ Training load $\left(\mathrm{TL}_{\mathrm{RPE}}\right)$ represents dimensionless term quantified by multiplying sRPE or sRIE by duration (intensity $\times$ duration)

'Only one observation (training session) during season period 5 for moderate and hard training sessions 
Table 3 Female Runners and Coach's Intensity (sRPE and sRIE) and Training Load (TLRPE) According to the Season Period and Intended Session Intensity (mean \pm SD)

\begin{tabular}{|c|c|c|c|c|c|c|c|c|c|c|c|c|}
\hline \multirow{3}{*}{ Season period } & \multicolumn{4}{|l|}{ Easy } & \multicolumn{4}{|l|}{ Moderate } & \multicolumn{4}{|l|}{ Hard } \\
\hline & \multicolumn{2}{|c|}{ Intensity $(\mathrm{AU})^{\mathrm{a}}$} & \multicolumn{2}{|c|}{ Training load $(\mathrm{AU})^{\mathrm{b}}$} & \multicolumn{2}{|c|}{ Intensity (AU) } & \multicolumn{2}{|c|}{ Training load (AU) } & \multicolumn{2}{|c|}{ Intensity (AU) } & \multicolumn{2}{|c|}{ Training load (AU) } \\
\hline & Athlete & Coach & Athlete & Coach & Athlete & Coach & Athlete & Coach & Athlete & Coach & Athlete & Coach \\
\hline 1 & $2.7 \pm 0.7$ & $1.3 \pm 0.5$ & $76 \pm 40$ & $38 \pm 9$ & $3.8 \pm 0.5$ & $3.4 \pm 0.6$ & $253 \pm 74$ & $230 \pm 32$ & $6.7 \pm 0.3$ & $6.8 \pm 1.0$ & $485 \pm 121$ & $485 \pm 97$ \\
\hline 2 & $2.3 \pm 0.6$ & $1.1 \pm 0.3$ & $72 \pm 52$ & $33 \pm 10$ & $3.7 \pm 1.1$ & $3.4 \pm 0.7$ & $244 \pm 70$ & $227 \pm 26$ & $6.6 \pm 1.2$ & $7.1 \pm 1.0$ & $491 \pm 117$ & $531 \pm 84$ \\
\hline 3 & $2.6 \pm 0.5$ & $1.2 \pm 0.5$ & $103 \pm 61$ & $54 \pm 10$ & $3.6 \pm 0.4$ & $3.6 \pm 0.6$ & $285 \pm 106$ & $281 \pm 26$ & $7.1 \pm 0.8$ & $7.3 \pm 0.9$ & $529 \pm 114$ & $543 \pm 71$ \\
\hline 4 & $2.5 \pm 0.8$ & $1.3 \pm 0.5$ & $105 \pm 54$ & $63 \pm 14$ & $3.5 \pm 0.3$ & $3.8 \pm 0.5$ & $261 \pm 113$ & $286 \pm 51$ & $7.2 \pm 1.0$ & $7.7 \pm 0.6$ & $511 \pm 125$ & $548 \pm 84$ \\
\hline $5^{c}$ & $2.0 \pm 0.7$ & $1.5 \pm 0.6$ & $77 \pm 57$ & $56 \pm 15$ & 5.2 & 5.0 & 328 & 335 & 9.4 & 10.0 & 585 & 627 \\
\hline Season average & $2.5 \pm 0.7$ & $1.3 \pm 0.5$ & $92 \pm 53$ & $64 \pm 12$ & $3.7 \pm 0.6$ & $3.6 \pm 0.6$ & $259 \pm 87$ & $244 \pm 34$ & $6.9 \pm 0.9$ & $7.3 \pm 1.0$ & $507 \pm 118$ & $551 \pm 84$ \\
\hline
\end{tabular}

$A U$ arbitrary units, SRPE session rating of perceived exertion, $s R I E$ sessions rating of intended exertion, $T L_{R P E}$ training load

antensity assessed as SRPE by athletes or SRIE by coaches on 1-10 scale [10]

${ }^{b}$ Training load $\left(T_{\mathrm{RPE}}\right.$ ) represents dimensionless term quantified by multiplying sRPE or sRIE by duration (intensity $\times$ duration)

cOnly one observation (training session) during season period 5 for moderate and hard training sessions
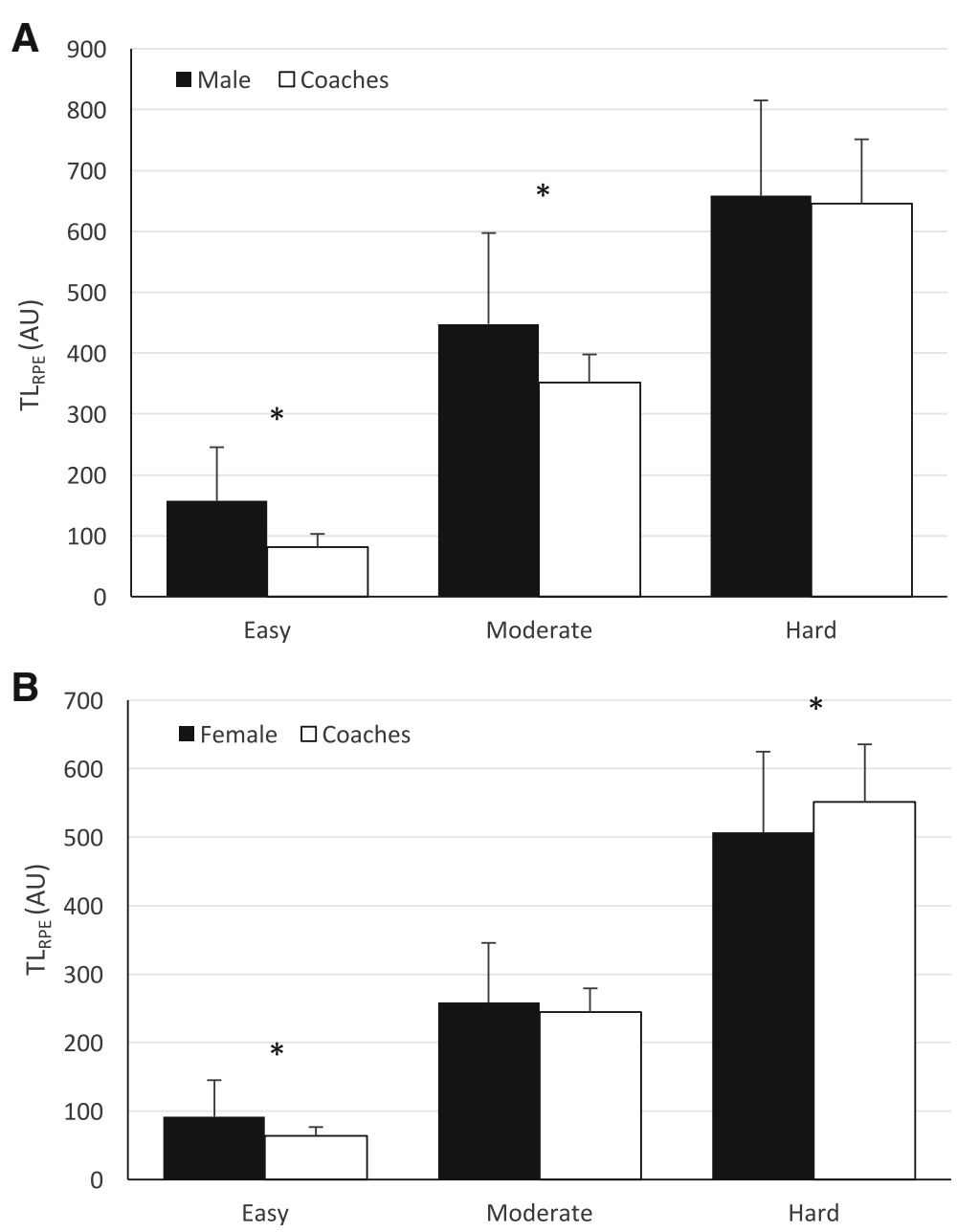

Fig. 1 Comparison of average training load $\left(T L_{R P E}\right.$ ) between coaches and male runners (a) and between coaches and female runners (b) for easy, moderate, and hard training sessions throughout the cross-country season. AU arbitrary units; asterisk indicates significantly different, $p<0.001$ 


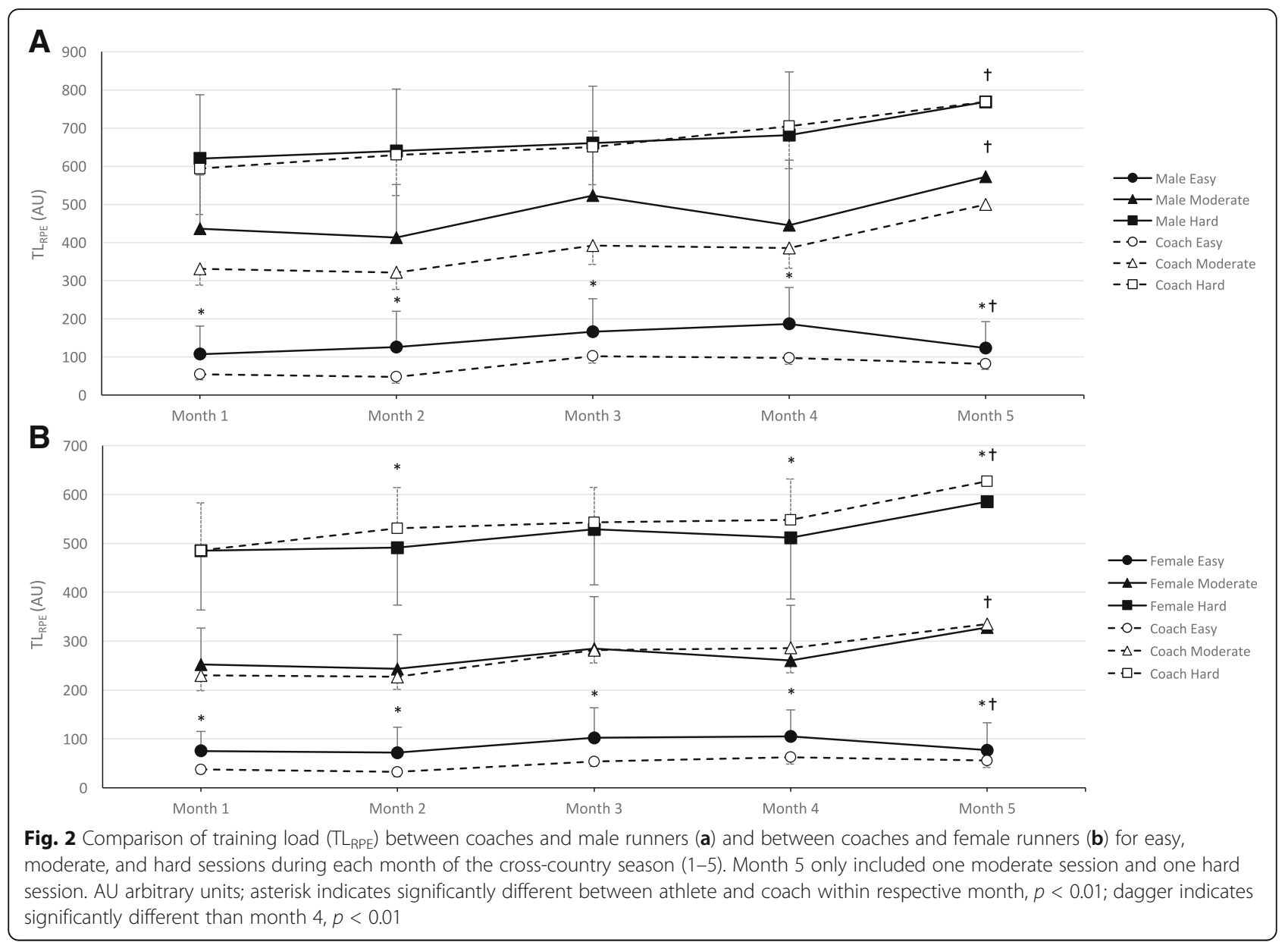

females (Fig. 2). There were no significant differences between male athletes and coaches for moderate or hard sessions each month in regard to rating of intensity (Table 2, $p>0.05$ ) or $\mathrm{TL}_{\mathrm{RPE}}$ (Fig. 2, Table 2, $p>0.05)$. However, months $1-3$ for men's intensity approached statistical significance $(p=0.17, p=0.06$, $p=0.31$, respectively). There were also no differences between females and coach's moderate intensity or $\mathrm{TL}_{\mathrm{RPE}}(p>0.05)$ during any month. However, during months 2,4 , and 5 , there were significant differences in intensity and $\mathrm{TL}_{\mathrm{RPE}}$ during hard sessions $(p<0.01)$ between female athletes and coaches. Session RPE and $\mathrm{TL}_{\mathrm{RPE}}$ for moderate sessions tended to undulate from month to month throughout the season; however, there was a significant $(p<0.001)$ increase in moderate intensity $\mathrm{TL}_{\mathrm{RPE}}$ during month 5 for both males and females (Fig. 2). Similarly, hard sessions tended to increase $(p>0.05)$ during each month throughout the season with a significant $(p<0.001)$ increase in month 5 (the NCAA Cross-Country National Championship Competition) respective to month 4 (Fig. 2).

\section{Discussion}

The aim of the current study was to investigate and compare the perceptions of training dose between coaches and male and female cross-country runners over a full competitive cross-country season. In general, athletes tended to perceive training as closer to moderate intensity throughout the season regardless of the intended session intensity by the coach. Likewise, for coach-intended easy and moderate sessions, male and female athletes reported higher intensity and training loads. For intended hard days, there was no difference between male runners and coaches, whereas females were significantly lower.

The discrepancy between runners' and coaches' perceptions of $\mathrm{TL}_{\mathrm{RPE}}$ in the current study depended on the training intensity. Previous studies have shown during hard training sessions (i.e., $\mathrm{RPE}>5$ ), the $\mathrm{sRPE}$ and $\mathrm{TL}_{\mathrm{RPE}}$ experienced by the athletes are lower than planned by the coaches $[9,10,15,18,19,23,25]$. Our results agree with this finding. Female runners consistently reported lower sRPE and $\mathrm{TL}_{\mathrm{RPE}}$ than coaches during hard sessions throughout the season (Fig. 2, Table 3), while male 
runners varied from month to month (Fig. 2, Table 2) but on average there was no difference ( $\mathrm{ES}=0.03, p=0.68$ ) throughout the season (Fig. 1). The discrepancy between athletes and coaches could be psychophysiological in nature. The performance of athletes is enhanced primarily as a response to high-intensity and/or long duration training sessions [10]. Therefore, often times in running, the athletes are informed ahead of time by the coaches what the hard workouts are going to be to prepare mentally and physically for such sessions. In the build-up to these hard sessions, athletes may actually mentally prepare for hard workouts to be harder than they actually are and, upon completion, realize it was easier than anticipated. Alternatively, [9] suggested that coaches may actually overprescribe the intensity of hard training sessions because the overall load of the training program may be too high.

Another explanation for the small to negligible differences during moderate to hard session in our study could be the fact that of the 25 runners in the study, all but two had been under the guidance of the same coaches for at least 2 years and all athletes had been performing run-specific training for at least 5 years. Previous research has shown greater agreement in perception of training intensity in experienced versus inexperienced athletes $[9,15]$. It would appear that for these athletes, training in the same system and under the supervision of the same coaches for 2 to 4 years has taught them how training is communicated on a daily basis and they trust the coach's expectations in terms of duration and intensity of each hard training session. Stewart and Hopkins [23] showed that trained swimmers also complied with prescribed distances and rest intervals during hard training sessions but were less effective in judging the intensity of swim training. This is not the case in all training programs, such that runners in another study regularly failed to comply with coach expectations in regard to the distance to be run and pace desired [10].

Accordingly, during easy (i.e., RPE $<3$ ) and moderate (i.e., RPE 3-5) sessions, sRPE and $T L_{R P E}$ were greater than that intended by the coaches. This tendency toward perception of moderate training loads is similar to that reported previously in other endurance runners and swimmers [10, 15, 25] as well as soccer players [9]. Possibly, this discrepancy between athletes and coach's perceptions of intensity and $\mathrm{TL}_{\mathrm{RPE}}$ during easy and moderate sessions could be related to differences in supervision of athletes during these training sessions compared to hard sessions. In this study, the coaches were physically present during the entire hard training sessions whereas during easy and moderate sessions athletes were often given instructions and sent out for the majority of their run without supervision. It could be that the athletes in this study tended to overtrain on easy and moderate days when the coaches were not present to adjust their intensity or groups each athlete was running with accordingly. The fact that crosscountry is a team sport and only a finite number of runners can compete in championship events may also partially explain this phenomenon. To convince the coach, runners may feel the need to perform above desired training intensities to show their superior fitness levels compared to teammates [9]. Since easy or moderate training sessions typically follow hard sessions, another explanation may be that coaches may have a misconception of the athlete's physiological state following the previous session load(s) [19]. Although coaches expect an easy training session the day following a hard session, it is possible that athletes are not recovered physically or psychologically enough to perceive such training as easy.

In collegiate cross-country running, while the training and racing are performed as an individual athlete, workouts regardless of intensity are often executed in small groups, making it easier for coaches to plan, control, and adjust exercise intensity depending on the day. With the planning of training and attempting to optimize performance on race day, coaches should keep in mind the physical and psychosocial characteristics that affect the internal load of each runner on the team. How to target intended training load is a complex procedure for coaches and requires an accurate analysis of data collection through objective and subjective observations of the athlete both in real-time and within the context of the present, past, and future training blocks, while also taking into account their own experience and training philosophy $[12,20]$. Accordingly, runners in the present study were regularly relegated to other training groups throughout the season and within training sessions themselves based on observations from when the coaches were present, particularly during moderate and hard sessions.

The tendency for athletes to regress toward perceptions of moderate training loads may from a theoretical standpoint have important implications for training athletes $[9,10,25]$. It has been previously suggested that this decrease in the day-to-day variability in training load may increase the risk of overtraining, injuries, illness, and maladaptation to the previous training sessions [10, 23]. Although injuries, illness, or markers of overtraining syndrome were not recorded in the present study, there were several incidents throughout the season that caused athletes to miss multiple training days. Whether these occurrences were correlated to or caused by the regression to moderate training loads is unknown; however, we can note that none of the athlete's experiences forced them to miss the remainder of the season. Furthermore, we found no reason to believe 
the athletes experienced any sort of decrements in running performance, particularly during the latter parts of the season given the success of the two teams discussed earlier.

\section{Conclusions}

In conclusion, our results indicate that there is a systematic difference between coaches and male and female cross-country runner intentions and perceptions of easy, moderate, and hard intensity training sessions throughout a competitive season. The rationale for this has not been fully elucidated but may be related to differences in coaching supervision during easy and hard training sessions, physiological and psychosocial factors before, during, and after training sessions, communication between coaches and athletes, and athlete experience. Given the success of the athletes in this study, these results show how a simple system for monitoring training such as the sRPE method may improve control of training variables and provide a useful tool for coaches to evaluate training load placed on athletes on a day-to-day basis, in a simple, responsive way $[4,25]$. Future studies should examine the link between perceptions of effort following moderate to hard training sessions or following long durations of training sessions.

\author{
Abbreviations \\ ANOVA: Analysis of variance; AU: Arbitrary units; ES: Effect size; \\ NCAA: National Collegiate Athletics Association; RPE: Rating of perceived \\ exertion; SD: Standard deviation; SRIE: Session rating of intended exertion; \\ SRPE: Session rating of perceived exertion; TLRPE: Training load; \\ TRIMP: Training impulse
}

\section{Acknowledgements}

The author would like to thank Alex McBride and Brianna King for their assistance with portions of the data analysis. The author is also very grateful to the runners and coaches at Grand Valley State University for allowing him to perform this investigation with them.

\section{Funding}

No financial support was received for the conduct of this study or preparation of this manuscript.

\section{Availability of Data and Materials \\ Not applicable}

\section{Ethics Approval and Consent to Participate}

The study was approved by the Grand Valley State University Human Research Review Committee (Reference \#: 14-206-H), and all participants provided informed written consent to participate.

\section{Consent for Publication}

Not applicable.

\section{Competing Interests}

The author declares that he has no competing interests.

\section{Publisher's Note}

Springer Nature remains neutral with regard to jurisdictional claims in published maps and institutional affiliations.
Received: 4 July 2017 Accepted: 10 October 2017

Published online: 17 October 2017

\section{References}

1. Foster C, Daines E, Hector L, Snyder AC, Welsh R. Athletic performance in relation to training load. Wis Med J. 1996;95:370-4.

2. Foster C, Daniels J, Yarbrough R. Physiological and training correlates of marathon running performance. Aust J Sports Med. 1977;9:58-61.

3. Foster C, Hector LL, Welsh R, Schrager M, Green MA, Snyder AC. Effects of specific versus cross-training on running performance. Eur J Appl Physiol. 1995:70:367-72

4. Foster C, Rodrigues-Marroyo J, de Koning J. Monitoring training loads: the past, the present, and the future. Int J Sports Physiol Perform. 2017:12:2-8.

5. Neuhof J. Structure and yearly training build-up in middle and long distance runners. New Stud Athlet. 1990;5:69-81.

6. Laursen PB, Jenkins DG. The scientific basis for high-intensity interval training: optimising training programmes and maximising performance in highly trained endurance athletes. Sports Med. 2002;32:53-73.

7. Foster C, Florhaug JA, Franklin J, Gottschall L, Hrovatin LA, Parker S, et al. A new approach to monitoring exercise training. J Strength Cond Res. 2001; 15:109-15.

8. Morton RH, Fitz-Clarke JR, Banister EW. Modeling human performance in running. J Appl Physiol (1985). 1990;69:1171-7.

9. Brink MS, Frencken WG, Jordet G, Lemmink KA. Coaches' and players' perceptions of training dose: not a perfect match. Int I Sports Physiol Perform. 2014:9(3):497-502.

10. Foster C, Heimann KM, Esten PL, Brice G, Porcari JP. Differences in perceptions of training by coaches and athletes. S Afr J Sports Med. 1991;8:3-7.

11. Impellizzeri FM, Rampinini E, Coutts AJ, Sassi A, Marcora SM. Use of RPEbased training load in soccer. Med Sci Sports Exerc. 2004;36:1042-7.

12. Kiely J. Periodization paradigms in the 21st century: evidence-led or tradition-driven? Int J Sports Physiol Perform. 2012;7:242-50.

13. Foster C. Monitoring training in athletes with reference to overtraining syndrome. Med Sci Sports Exerc. 1998;30:1164-8

14. Brink MS, Visscher C, Coutts AJ, Lemmink KA. Changes in perceived stress and recovery in overreached young elite soccer players. Scand J Med Sci Sports. 2012;22:285-92

15. Barroso R, Cardoso RK, do Carmo EC, Tricoli V. Perceived exertion in coaches and young swimmers with different training experience. Int I Sports Physiol Perform. 2014:9:212-6.

16. Brink MS, Kersten AW, Frencken WGP. Understanding the mismatch between coaches' and players' perceptions of exertion. Int I Sports Physiol Perform. 2017;12:562-8.

17. Doeven SH, Brink MS, Frencken WG, Lemmink KA. Impaired player-coach perceptions of exertion and recovery during match congestion. Int I Sports Physiol Perform. 2017:1-20. http://journals.humankinetics.com/doi/abs/10. 1123/ijspp.2016-0363?url_ver=Z39.88-2003\&rfr_id=ori:rid:crossref.org\&rfr_ dat=cr_pub\%3dpubmed.

18. Imamura H, Yoshimura Y, Uchida K, Tanaka A, Nishimura S, Nakazawa AT Heart rate, blood lactate responses and ratings of perceived exertion to 1,000 punches and 1,000 kicks in collegiate karate practitioners. Appl Hum Sci. 1997;16:9-13.

19. Murphy AP, Duffield R, Kellett A, Reid M. Comparison of athlete-coach perceptions of internal and external load markers for elite junior tennis training. Int J Sports Physiol Perform. 2014:9:751-6.

20. Rabelo FN, Pasquarelli BN, Goncalves B, Matzenbacher F, Campos FA, Sampaio J, et al. Monitoring the intended and perceived training load of a professional futsal team over 45 weeks: a case study. J Strength Cond Res. 2016:30:134-40

21. Redkva PE, Gregorio da Silva S, Paes MR, Dos-Santos JW. The relationship between coach and player training load perceptions in professional soccer. Percept Mot Skills. 2016;124(1):264-76.

22. Rodriguez-Marroyo JA, Medina J, Garcia-Lopez J, Garcia-Tormo JV, Foster C. Correspondence between training load executed by volleyball players and the one observed by coaches. J Strength Cond Res. 2014;28:1588-94.

23. Stewart AM, Hopkins WG. Swimmers' compliance with training prescription. Med Sci Sports Exerc. 1997;29:1389-92.

24. Viveiros L, Costa E, Moreira A, Nakamura F, Aoki M. Training load monitoring in judo: comparison between training load intensity planned by the coach 
and the intensity experienced by the athlete. Rev Bras Med Esporte. 2012; 17:266-9.

25. Wallace LK, Slattery KM, Coutts AJ. The ecological validity and application of the session-RPE method for quantifying training loads in swimming. J Strength Cond Res. 2009;23:33-8.

26. Day ML, McGuigan MR, Brice G, Foster C. Monitoring exercise intensity during resistance training using the session RPE scale. J Strength Cond Res. 2004;18:353-8.

27. Hopkins WG. Spreadsheets for analysis of controlled trials, with adjustment for a subject characteristic. Sportscience. 2006;10:46-50.

28. Barnes KR, Hopkins WG, McGuigan MR, Kilding AE. Warm-up with a weighted vest improves running performance via leg stiffness and running economy. J Sci Med Sport. 2015;18:103-8.

29. Hopkins WG, Marshall SW, Batterham AM, Hanin J. Progressive statistics for studies in sports medicine and exercise science. Med Sci Sports Exerc. 2009; 41:3-13.

\section{Submit your manuscript to a SpringerOpen ${ }^{\circ}$ journal and benefit from:}

- Convenient online submission

- Rigorous peer review

- Open access: articles freely available online

- High visibility within the field

- Retaining the copyright to your article

Submit your next manuscript at $\boldsymbol{\sim}$ springeropen.com 